\title{
Determination of musculoskeletal system pain, physical activity intensity, and prolonged sitting of university students using smartphone
}

\author{
Sema Can ${ }^{1}$, Ayda Karaca ${ }^{2}$ \\ ${ }^{1}$ Faculty of Sports Sciences, Hitit University, Çorum, Turkey; ${ }^{2}$ Faculty of Sports Sciences, Hacettepe University, Ankara, \\ Turkey
}

\section{Summary}

Study aim: The purpose of this study was to examine smartphone-using university students' musculoskeletal system pain complaints, duration of smartphone and computer usage, participation in moderate-vigorous physical activities (MVPA), and prolonged sitting time.

Material and methods: This study was conducted on Hitit University students ( $\mathrm{n}=387 ; 206$ female, 181 male) in the province of Çorum. The International Physical Activity Questionnaire-Short Form (IPAQ-SF), the Physical Activity Assessment Questionnaire (PAAQ) (sports/exercise activities section), and a personal information form prepared by the researchers were used as data collection tools. Descriptive statistics and the t-test were used to determine differences between groups. The Pearson chi-square test was used to examine the relationship between categorical variables.

Results: It was observed that half of the participants with musculoskeletal system pain complaints (54.5\%) feel the pain in all four areas (neck, shoulder, upper and lower back). There was no statistically significant relationship between physical activity intensity and pain complaint $(\mathrm{p}>0.05)$. The students with musculoskeletal pain complaints spend more time on the smartphone and computer than students who do not have pain complaints $(\mathrm{p}<0.05)$. During electronic device usage, the students who are in the low-intensity physical activity category spend more time sitting down than students in the moderate/vigorous intensity physical activity category $(\mathrm{p}<0.05)$.

Conclusions: In consequence, information can be provided about the importance of reducing sitting time during smartphone use and increasing the duration of moderate/vigorous-intensity physical activity (PA) so awareness can be raised on the issue among university students.

\section{Keywords: Musculoskeletal system pain - Physical activity - Smartphone}

\section{Introduction}

Electronic devices are the most popular tools that young people have chosen for their free time in recent years $[12,36]$. Smartphones have become more and more preferred with the addition of features of a portable small PC, such as media player, digital camera, e-mail, and GPS navigation [1]. In addition to talking and texting, smartphones are used for many purposes such as internet surfing, shopping, getting information easily and quickly, listening to music, making simple designs, and playing games [23, 29]. Because of capacity increase and widening usage areas, smartphones are becoming more and more involved in everyday life $[17,23]$. It was shown in Cakır and Demir's [6] study that $76.7 \%$ of university students use smartphones and $87.7 \%$ of students who do not use smartphones were willing to buy one. According to the Turkish Statistical Institute (TUIK) "Information and Communication Technology (ICT) Usage Survey on Households and Individuals (2004-2018)" in the last 15 years the computer and internet usage rates have increased significantly among young people aged between 16 and 24 in Turkey [42].

The usage of screen-based media including smartphones, computers, etc., is negatively affecting the health and quality of life [15]. Excessive use of smartphones has been associated with inactive lifestyle [24, 27, 31, 32, $36,38]$, and inactive lifestyle can cause musculoskeletal complaints [14]. Smartphones can also cause physical, 
psychological and social problems [32], anxiety, stress, headache, and sleep problems [12, 24, 27, 31, 36]. Incorrect posture, usually caused by tilting the head forward during use of the smartphone, causes increased weight on cervical vertebrae and neck muscles [1], and many musculoskeletal complaints including the spinal column $[1,19,22,48]$. Todd et al. [38] stated that long-term sitting and long-term static posture may increase upper and lower back pain risk, while Myrtveit et al. [25] stated that excessive time spent on screen-based activities can increase the risk of neck and shoulder pain. Since the musculoskeletal complaints are acute, chronic and repetitive, it is considered as a public health problem $[11,12]$. The purpose of this study was to examine the smartphone using university students' 1) musculoskeletal system pain complaints, 2) duration of smartphone and computer usage, 3) participation in moderate-vigorous physical activities (MVPA), and 4) prolonged sitting time.

\section{Material and methods}

\section{Sampling}

This research was conducted in May-June of the 20162017 academic year on 510 students educating at Hitit University in Çorum. Partially completed surveys were

Table 1. Frequency distribution of the students' pain complaints, physical activity participation, and some other parameters

\begin{tabular}{|c|c|c|c|c|c|c|c|}
\hline \multirow[t]{2}{*}{ Variable } & \multirow[t]{2}{*}{ Category } & \multicolumn{2}{|c|}{$\begin{array}{l}\text { Female } \\
(\mathrm{n}=206)\end{array}$} & \multicolumn{2}{|c|}{$\begin{array}{c}\text { Male } \\
(\mathrm{n}=181)\end{array}$} & \multicolumn{2}{|c|}{$\begin{array}{c}\text { Total } \\
(\mathrm{n}=387)\end{array}$} \\
\hline & & $\mathrm{f}$ & $\%$ & $\mathrm{f}$ & $\%$ & $\mathrm{f}$ & $\%$ \\
\hline \multirow{2}{*}{$\begin{array}{l}\text { Regular sport or exercise during the } \\
\text { previous month }\end{array}$} & Yes & 33 & 16.0 & 57 & 31.5 & 90 & 23.3 \\
\hline & No & 173 & 84.0 & 124 & 68.5 & 297 & 76.7 \\
\hline \multirow{2}{*}{$\begin{array}{l}\text { Meeting recommendation of } 150 \text { minutes } \\
\text { MVPA in the previous week }\end{array}$} & Yes & 30 & 14.6 & 40 & 22.1 & 70 & 18.1 \\
\hline & No & 176 & 85.4 & 141 & 77.9 & 317 & 81.9 \\
\hline \multirow{2}{*}{ Duration of sitting } & $<4$ hours/day & 59 & 28.6 & 60 & 33.1 & 119 & 30.7 \\
\hline & $\geq 4$ hours/day & 147 & 71.4 & 121 & 66.9 & 268 & 69.3 \\
\hline \multirow{2}{*}{ Duration of computer usage } & $<4$ hours/day & 192 & 93.2 & 140 & 77.3 & 332 & 85.8 \\
\hline & $\geq 4$ hours/day & 14 & 6.8 & 41 & 22.7 & 55 & 14.2 \\
\hline \multirow{2}{*}{ Duration of smartphone usage } & $<4$ hours/day & 36 & 17.5 & 64 & 35.3 & 100 & 25.8 \\
\hline & $\geq 4$ hours/day & 170 & 82.5 & 117 & 64.7 & 287 & 74.2 \\
\hline \multirow{2}{*}{$\begin{array}{l}\text { Total duration of computer and } \\
\text { smartphone usage }\end{array}$} & $<4$ hours/day & 22 & 10.7 & 30 & 16.6 & 52 & 13.4 \\
\hline & $\geq 4$ hours/day & 184 & 89.3 & 151 & 83.4 & 335 & 86.6 \\
\hline \multirow{5}{*}{ Purpose of smartphone usage } & Talking & 48 & 23.3 & 34 & 18.8 & 82 & 58.4 \\
\hline & Social media & 135 & 65.6 & 105 & 58.0 & 240 & 62.0 \\
\hline & Games & 4 & 1.9 & 12 & 6.6 & 16 & 4.1 \\
\hline & Research & 11 & 5.3 & 11 & 6.1 & 22 & 5.7 \\
\hline & Other & 8 & 3.9 & 19 & 10.5 & 27 & 7.0 \\
\hline \multirow{3}{*}{ General health perception } & Poor & 7 & 3.4 & 6 & 3.3 & 13 & 3.4 \\
\hline & Fair & 102 & 49.5 & 63 & 34.8 & 165 & 42.6 \\
\hline & Good & 97 & 47.1 & 112 & 61.9 & 209 & 54.0 \\
\hline \multirow{2}{*}{ Pain complaint } & Yes & 105 & 51.0 & 51 & 28.2 & 156 & 40.3 \\
\hline & No & 101 & 49.0 & 130 & 71.8 & 231 & 59.7 \\
\hline \multirow{4}{*}{ Pain complaint area } & & \multicolumn{2}{|c|}{$(\mathrm{n}=105)$} & \multicolumn{2}{|c|}{$(\mathrm{n}=51)$} & \multicolumn{2}{|c|}{$(\mathrm{n}=156)$} \\
\hline & $\begin{array}{l}\text { Neck and shoulder, upper } \\
\text { and lower back }\end{array}$ & 65 & 61.9 & 20 & 39.2 & 85 & 54.5 \\
\hline & Neck and shoulder & 18 & 17.1 & 10 & 19.6 & 28 & 17.9 \\
\hline & Upper and lower back & 22 & 21.0 & 21 & 41.2 & 43 & 27.6 \\
\hline
\end{tabular}


excluded from the study. The data of 387 students, $206 \mathrm{fe}-$ male (age: $21.79 \pm 1.87$ years; height: $164.48 \pm 5.63 \mathrm{~cm}$; body weight: $58.02 \pm 8.93 \mathrm{~kg}$; body mass index: $21.43 \pm 3.03 \mathrm{~kg} / \mathrm{m}^{2}$ ) and 181 male (age: $21.79 \pm 1.87$ years; height: $177.20 \pm 6.34 \mathrm{~cm}$; body weight: $75.79 \pm 12 \mathrm{~kg}$; body mass index: $24.09 \pm 3.30 \mathrm{~kg} / \mathrm{m}^{2}$ ) were taken into consideration.

\section{Data collection}

The International Physical Activity QuestionnaireShort Form (IPAQ-SF) developed by Craig et al. [8] and adapted to Turkish by Ozturk [30], the Physical Activity Assessment Questionnaire (PAAQ) (sports/exercise activities section) developed by Karaca et al. [18], and a data information form prepared by the present researchers (demographic information, smartphone and computer use, musculoskeletal system complaints, etc.) were used. The questions in the IPAQ-SF, PAAQ, and personal information form were prepared in an electronic environment and distributed to the students via smartphone through a mobile application and applied by the self-report method.

\section{Statistical analysis}

The mean, standard deviation, frequency (f), and percent $(\%)$ values of the variables were given as descriptive statistics. The t-test was used to determine differences between groups. The Pearson chi-square test was used to examine the relationship between categorical variables. All the statistical analyses were performed using the program IBM SPSS Statistics (version 23.0), and the significance level was set at 0.05 for all tests.

\section{Results}

Frequency (f) distribution of the students' pain complaints, physical activity participation, and some other parameters are given in Table 1.

It was found that approximately $3 / 4$ of the participant students had not been exercising regularly for the last one month and had not reached the recommended PA level in the last week (150 minutes/week MVPA), about 2/3 of them had been sitting more than 4 hours a day. Although the majority of the 387 students who participated in the study had fair or good general health perception, nearly half of the students had pain complaints. Approximately half of the participants who had pain complaints felt pain in at least four areas (neck, shoulder, upper and lower back). Social media have a significant place among the purposes of smartphone usage (Table 1).

Table 2. Frequency distribution of the students with and without pain complaints according to some variables

\begin{tabular}{|c|c|c|c|c|}
\hline & & Pain con & & \\
\hline & Yes $(n=156)$ & No $(n=231)$ & Total $(n=387)$ & $\chi^{2}$ \\
\hline & $f(\%)$ & $\mathrm{f}(\%)$ & $\mathrm{f}(\%)$ & (p) \\
\hline Posture & & & & \\
\hline Sitting & $106(67.9)$ & $168(72.7)$ & $274(70.8)$ & \\
\hline Standing & $4(2.6)$ & $8(3.5)$ & $12(3.1)$ & $\begin{array}{l}1.835 \\
(0.607)\end{array}$ \\
\hline Lying face down & $4(2.6)$ & $6(2.6)$ & $10(2.6)$ & \\
\hline Lying on the back & $42(26.9)$ & $49(21.2)$ & $91(23.5)$ & \\
\hline Duration of smartphone $\mathrm{u}$ & & & & \\
\hline$<4$ hours/day & $38(24.4)$ & $62(26.8)$ & $100(25.8)$ & 0.299 \\
\hline$\geq 4$ hours/day & $118(75.6)$ & $169(73.2)$ & $287(74.2)$ & $(0.637)$ \\
\hline Duration of computer usa & & & & \\
\hline$<4$ hours/day & $128(82.1)$ & $204(88.3)$ & $332(85.8)$ & 2.993 \\
\hline$\geq 4$ hours/day & $28(17.9)$ & $27(11.7)$ & $55(14.2)$ & $(0.084)$ \\
\hline $\begin{array}{l}\text { Total duration of compute } \\
\text { and smartphone usage }\end{array}$ & & & & \\
\hline$<4$ hours/day & $18(11.5)$ & $34(14.7)$ & $52(13.4)$ & 0.810 \\
\hline$\geq 4$ hours/day & $138(88.5)$ & $197(85.3)$ & $335(86.6)$ & $(0.368)$ \\
\hline Physical activity intensity & & & & \\
\hline Moderate/vigorous & $112(71.8)$ & $175(75.8)$ & $287(74.2)$ & 0.763 \\
\hline Low & $44(28.2)$ & $56(24.2)$ & $100(25.8)$ & $(0.382)$ \\
\hline
\end{tabular}


The students' preferred posture during smartphone use, the duration of smartphone and computer use, and the distribution of pain complaints according to physical activity intensity are given in Table 2 .

It was observed that the majority of the students were in a sitting position during smartphone use. There was no statistically significant relationship between pain complaint and posture $(p>0.05)$. Approximately $3 / 4$ of both students with and without pain complaints use the smartphone over 4 hours a day. There were no statistically significant relationships between physical activity intensity and pain complaints or between the duration of the smartphone + computer usage and pain complaints $(p>0.05)$ (Table 2).

The students with musculoskeletal pain complaints spent more time on the smartphone and computer than students who do not have pain complaints. $(\mathrm{p}<0.05)$ (Table 3$)$.

During electronic device usage, the students who were in the low-intensity physical activity category spent more time sitting down than students in the moderate/vigorous physical activity category $(\mathrm{p}<0.05)$. Depending on the duration of smartphone and computer usage, there was no statistically significant difference between the low and moderate/vigorous physical activity categories $(p>0.05)$ (Table 4).

\section{Discussion}

The smartphone and internet usage rates are increasing at a global level. As an emerging country, Turkey has the highest increase in rates for both having a smartphone and using the internet in the years between 2013 and 2015. The percentage of smartphone ownership increased from $17 \%$ in 2013 to $59 \%$ in 2015 [33]. According to the data published by TUIK in 2018, since 2004 the computer usage rate of young people aged between 16 and 24 has risen from $32.2 \%$ (females $21.1 \%$; males $44.4 \%$ ) to $68.2 \%$ (females $61.1 \%$; males $75.1 \%$ ) and the internet usage rate rose from $26.6 \%$ (females $15.9 \%$; males $38.3 \%$ ) to $90.7 \%$ (females 86.5\%; males 94.7\%) [42]. Cakir and Demir [6] stated that $76.7 \%$ of university students had smartphones and $87.7 \%$ of students who did not use a smartphone were willing to buy one.

In this study, the duration of smartphone and computer usage of the students with pain complaints was higher than

Table 3. Duration of smartphone and computer usage, and sitting time during electronic device usage depending on the pain complaint

\begin{tabular}{|c|c|c|c|c|}
\hline \multirow{3}{*}{ Duration (min/day) } & \multicolumn{2}{|c|}{ Pain } & \multirow{3}{*}{$\mathrm{t}$} & \multirow{3}{*}{$\mathrm{p}$} \\
\hline & Yes $(n=156)$ & No $(n=231)$ & & \\
\hline & Mean \pm SD & Mean \pm SD & & \\
\hline Duration of smartphone usage & $427.5 \pm 242.4$ & $379.1 \pm 232.0$ & 1.975 & $0.049 *$ \\
\hline Duration of computer usage & $124.1 \pm 138.3$ & $95.5 \pm 126.1$ & 2.103 & $0.036^{*}$ \\
\hline Total duration of computer and smartphone usage & $551.6 \pm 287.7$ & $474.7 \pm 261.5$ & 2.726 & $0.007 *$ \\
\hline Sitting time during electronic device usage & $121.18 \pm 95.26$ & $103.35 \pm 86.41$ & 1.910 & 0.057 \\
\hline
\end{tabular}

$*-\mathrm{p}<0.05$.

Table 4. Duration of smartphone and computer usage and sitting time during electronic device usage depending on physical activity intensity

\begin{tabular}{|c|c|c|c|c|}
\hline \multirow{3}{*}{ Duration (min/day) } & \multicolumn{2}{|c|}{ Physical activity intensity category } & \multirow{3}{*}{$\mathrm{t}$} & \multirow{3}{*}{$\mathrm{p}$} \\
\hline & $\begin{array}{l}\text { Moderate/vigorous-intensity PA } \\
\qquad(\mathrm{n}=287)\end{array}$ & $\begin{array}{l}\text { Low-intensity PA } \\
\quad(\mathrm{n}=100)\end{array}$ & & \\
\hline & Mean \pm SD & Mean \pm SD & & \\
\hline Duration of smartphone usage & $393.7 \pm 235.6$ & $412.9 \pm 242.1$ & -0.697 & 0.486 \\
\hline Duration of computer usage & $100.6 \pm 126.7$ & $125.5 \pm 144.2$ & -1.627 & 0.104 \\
\hline Total duration of computer and smartphone usage & $494.3 \pm 276.5$ & $538.4 \pm 268.0$ & -1.383 & 0.168 \\
\hline Sitting time during electronic device usage & $104.07 \pm 80.50$ & $129.10 \pm 112.54$ & -2.399 & $0.017 *$ \\
\hline
\end{tabular}

${ }^{*}-\mathrm{p}<0.05$. 
in students who did not have pain complaints. $(p<0.05)$ (Table 3). In some studies, it has been reported that there was a relationship between computer or smartphone use and musculoskeletal system disorders, especially neck and shoulder pain $[4,16,26]$. In the study of Alabdulwahab et al. [1] a statistically significant relationship was found between the Smartphone Addiction Scale (SAS) and the Neck Disability Index (NDI). In their study, Hakala et al. [10] examined adolescents in Finland and reported that more than 2-3 hours of computer use per day increases the risk of NSP. Noack-Cooper et al. [26] reported that the college students had pain complaints in their neck, trunk, upper extremity, and lower extremity but the neck was the most common site. Berolo et al. [4] stated that Canadian university student and staff who use the handheld mobile device were examined. The results showed that $84 \%$ of participants had pain in at least one part of their body, $46-52 \%$ had shoulder pain, and $68 \%$ had neck pain symptoms. In another study in China, an approximately $40 \%$ neck-shoulder pain rate and a $33 \%$ back pain rate were reported among young people using mobile devices [35]. According to TUIK [40] data, for individuals over 15 years old, complaints of the lower back area had increased from $22.5 \%$ to $27.1 \%$, and neck area complaints increased from $11.5 \%$ to $18.1 \%$ between the years $2008-2016$. In this study, about half of the students who have pain feel the pain in all four areas (neck, shoulder, upper and lower back). Similar to this study (Table 1), among Norwegian adolescents, the frequency of feeling neck and shoulder pain was higher in girls than in boys [25].

Numerous known, unknown, changeable, unchangeable, physical or psychological risk factors can lead to the musculoskeletal system symptoms [37, 48]. In this context, it has been stated that repetitive movements might trigger the pain. During smartphone use, remaining continuously in the same downward position might cause pain in the neck muscles due to the excessive contraction and tightness [48]. Noack-Cooper et al. [26] reported that students use computers in improper postures and they have pain in one or more parts of their bodies because of this poor posture. Guan et al. [9] stated that the posture, head, and neck flexion angles during the mobile phone use were associated with cervical pain and the duration of use can increase the pain complaint.

In this study, it was observed that the majority of the students were in a sitting position (70.8\%) during smartphone use and that there was no statistically significant relationship between pain complaints and posture (Table 2). Also, some studies indicate that in developed countries there is a relationship between computer use and pain symptoms [36]. Hakala et al. [12] stated that complaints of pain increase when the technology use increases; neck, shoulder and headache complaints were more frequent. Silva et al. [36] stated that musculoskeletal complaints were more frequent in individuals with high prevalence of electronic devices, and also the pain in the cervical and thoracolumbar area increases when the duration of these devices' usage increased ( $>4$ hours/day). In addition, studies indicated that use of the smartphone was associated with complaints of upper extremity and neck pain, and the long-term use of a touchscreen smartphone may also increase the risk of developing musculoskeletal symptoms such as chronic neck and shoulder pain [21, 45]. In this study, it was found that $3 / 4$ of the students with pain complaints use their smartphones for over 4 hours, the individuals who complained of pain had a longer duration of smartphone usage, but there was no statistically significant relationship between the percentage of smartphone use more/less than 4 hours and the presence/absence of pain complaints (Table 2). These findings are similar to those of Zapata et al.'s [48] study, which found no relationship between the duration of electronic gaming or computer use and pain complaints. In addition, as in this study, Yagc1 et al. [46] reported that the duration of computer use had no effect on neck pain in their research.

According to the "Information and Communication Technology (ICT) Usage Survey on Households and Individuals" published by the Turkish Statistical Institute [39], "social media" has the first rank among the internet usage purposes for $80.9 \%$ of the individuals who use the internet between the ages of 16 and 74. In a 2016 report [41], this percentage had increased to $82.4 \%$. Likewise, in this study, "social media" has the first place (62.0\%) among students' smartphone usage purposes. However, the percentage is lower than the data of TUIK 2015 and 2016 [41]. In the studies, it was stated that internet usage purposes for males are mainly consumer information processing (economic transactions) and research, while females prefer social media $[3,47]$. Similarly, in the present study, it was found that "social media" usage rates are $65.5 \%$ for females and $58 \%$ for males.

The World Health Organization (WHO) and American College of Sports Medicine (ACSM) have stated that at least 150 minutes of moderate-intensity or 75 minutes of vigorous-intensity exercise per week should be done regularly for a healthier and better life $[13,44]$. It is stated that an increase in the sitting time causes many health problems [7]. In this study, it was observed that the majority of the students did not participate in moderate/vigorous physical activities for more than 150 minutes per week, and only about $1 / 4$ of them had been exercising regularly for the last month (Table 1). In many studies, it has been pointed out that most of the university students did not have enough physical activity [20,28, 34, 43] and spent a lot of time on screen-based activity [5]. These results were similar to this study (Table 1). In the present study, about $2 / 3$ of the students have more than 4 hours of sitting time and smartphone use. These rates were higher in 
females than in males (Table 1). Shoulder and neck pain, which was very common in adolescents, has been associated with both long-term sitting and high-intensity PA [2]. Myrtveit et al. [25] reported that physical activity reduces the risk of neck and shoulder pain (NSP), and individuals with NSP join in physical activities less. In some studies, different findings have been reported, such as no relationship between PA and NSP, or that PA increases NSP [19]. In this study, no statistically significant relationship was found between physical activity intensity and pain complaints (Table 4).

\section{Conclusion}

In consequence, information must be given about the importance of decreasing prolonged sitting time and increasing engagement of MVPA including daily life activities. The strategies to promote physical activity must be covered by individual methods of behavior change, environmental arrangements and policy support. Interventions must be conducted in community settings and university settings. In this increasing trend toward widespread technology and smartphone usage, to increase the duration of PA, information should be provided about the step number apps on smartphones and awareness must be raised on the issue. Because the intensity of the exercise is essential for protecting and improving health, simple prescriptions such as 3000 steps $/ 30$ minutes or 1000 steps $/ 10$ minutes $\times 3$ can be proposed to the students.

\section{Conflict of interest: Authors state no conflict of interest.}

\section{References}

1. AlAbdulwahab S.S., Kachanathu S.J., AlMotairi M.S. (2017) Smartphone use addiction can cause neck disability. Musculoskeletal Care,15(1): 10-12.

2. Auvinen J,. Tammelin T., Taimela S., Zitting P., Karppinen J. (2007) Neck and shoulder pains in relation to physical activity and sedentary activities in adolescence. Spine, 32(9): 1038-1044.

3. Balc S., Ayhan B.A. (2007) survey on internet uses and gratificitions of university schools. J. Selçuk Commun., 5(1): 174-197.

4. Berolo S., Wells R.P., Amick B.C. (2011) Musculoskeletal symptoms among mobile hand-held device users and their relationship to device use: A preliminary study in a Canadian University Population. Appl. Ergon., 42(2): 371-378.

5. Caglar E., Bilgili N., Karaca A., Deliceoglu G. (2017) Screen time differences among Turkish university stu- dents as indicator for sedentary lifestyle and inactivity. Croat. J. Educ., 19(4): 1105-1130.

6. Cakır F., Demir B.N. (2014) A Study on determining preferences of university students' purchasing smartphone. Dokuz Eylul University Faculty of Economics and Administrative Sciences, 29(1): 213-243.

7. Chau J.Y., Daley M., Dunn S., Srinivasan A., Do A., Bauman A.E., van der Ploeg H.P. (2014) The effectiveness of sit-stand workstations for changing office workers' sitting time: results from the Stand@Work randomized controlled trial pilot. Int. J. Behav. Nutr. Phys. Act., 11: 127. DOI: 10.1186/s12966-014-0127-7.

8. Craig C.L., Marshall A.L., Sjöström M., Bauman A.E., Booth M.L., Ainsworth B.E., Pratt M., Ekelund U., Yngve A., Sallis J.F., Oja P. (2003) International physical activity questionnaire: 12 -country reliability and validity. Med. Sci. Sports Exerc., 35(8): 1381-1395.

9. Guan X., Fan G., Chen Z., Zeng Y., Zhang H., Hu A., Gu G., Wu X., Gu X., He S. (2016) Gender difference in mobile phone use and the impact of digital device exposure on neck posture. Ergonomics, 59(11): 1453-1461.

10. Hakala P.T., Rimpelä A.H., Saarni L.A., Salminen J.J. (2006) Frequent computer-related activities increase the risk of neck-shoulder and low back pain in adolescents. Eur. J. Public Health, 16(5): 536-541.

11. Hakala P.T., Saarni L., Ketola R., Rahkola E.T., Salminen J.J., Rimpelä A.H. (2010) Computer-associated health complaints and sources of ergonomic instructions in computer-related issues among Finnish adolescents: A cross-sectional study. BMC Public Health, 10: 11. DOI: 10.1186/1471-2458-10-11.

12. Hakala P.T., Saarni L.A., Punamäki R.L., Wallenius M.A., Nygård C.H., Rimpelä A.H. (2012) Musculoskeletal symptoms and computer use among Finnish adolescents-pain intensity and inconvenience to everyday life: A cross-sectional study. BMC Musculoskeletal Disorders, 13(1): 41.

13. Haskell W.L., Lee I.M., Pate R.R., Powell K.E., Blair S.N., Franklin B.A., Macera C.A., Heath G.W., Thompson P.D., Bauman A. (2007) Physical activity and public health: updated recommendation for adults from the American College of Sports Medicine and the American Heart Association. Med. Sci. Sports Exerc., 39(8): 1423-1434.

14. Holth H.S., Werpen H.K.B., Zwart J.A., Hagen K. (2008) Physical inactivity is associated with chronic musculoskeletal complaints 11 years later: results from the Nord-Trøndelag Health Study. BMC Musculoskeletal Disorders., 9(1): 159.

15. Iannotti R.J., Kogan M.D., Janssen I., Boyce W.F. (2009) Patterns of adolescent physical activity, screen-based media use, and positive and negative health indicators in the US and Canada. J. Adolesc. Health, 44(5): 493-499. 
16. Jenkins M., Menéndez C.C., Amick B.C., Tullar J., Hupert N., Robertson M.M., Katz J.N. (2007) Undergraduate college students' upper extremity symptoms and functional limitations related to computer use: a replication study. Work, 28(3): 231-238.

17. Karaarslan I.A., Budak L. (2012) Research on the use of mobile phone features by university students and its impact on their communication practices in everyday life. Journal of Yasar University, 26(7): 4548-4571.

18. Karaca A., Ergen E., Koruç Z. (2000) The reliability of and the validity of the physical activity assessment questionnarie (PAAQ). Hacettepe J. Sport Sci., 11(1): 17-28.

19. Kelly G., Dockrell S., Galvin R. (2009) Computer use at school: its effect on posture in discomfort in schoolchildren. Work, 32: 321-328.

20. Kızar O., Kargün M., Togo O.T., Biner M., Pala A. (2016) The Examining of The Physical Activity Level of The University Students. Marmara University J. Sport Sci., 1(1): 61-72.

21. Kim G.Y., Ahn C.S., Jeon H.W. (2012) Effects of the use of smartphones on pain and muscle fatigue in the upper extremity. J. Phys. Ther. Sci., 24(12): 1255-1258.

22. Kim H.J., Kim J.S. (2015) The relationship between smartphone use and subjective musculoskeletal symptoms and university students. J. Phys. Ther. Sci., 27(3): 575-579.

23. Kuyucu M. (2017) Use of smartphone and problematic of smart phone addiction in young people: "smart phone (Colic)" University Youth. Global Media Journal TR Edition, 7(14): 328-359.

24. Milde-Busch A., von Kries R., Thomas S., Heinrich S., Straube A., Radon K. (2010) The association between use of electronic media and prevalence of headache in adolescents: results from a population-based cross-sectional study. BMC Neurol., 10: 12. DOI: 10.1186/1471-237710-12.

25. Myrtveit S.M., Sivertsen B., Skogen J.C., Frostholm L., Stormark K.M., Hysing M. (2014) Adolescent neck and shoulder pain - the association with depression, physical activity, screen-based activities, and use of health care services. J. Adolesc. Health, 55(3): 366-372.

26. Noack-Cooper K.L., Sommerich C.M., Mirka G.A. (2009) College students and computers: Assessment of usage patterns and musculoskeletal discomfort. Work, 32(3): 285-298.

27. Noyan C.O., Enez Darcın A., Nurmedov S., Y1lmaz S., Dilbaz N. (2015) Validity and reliability of the Turkish version of the smartphone addiction scale-short version among university students. Anatolian J. Psychiatry, 16: $73-81$.

28. Olcucu B., Vatansever S., Ozcan G., Celik A., Paktaş Y. (2015) The relationship between depression, anxiety and physical activity level among university students. Int. J. Turkish Educ. Sci., 294-303.
29. Ozkocak Y. (2016) Turkish smartphone users' mobile application preferences for recreation. Global Media Journal TR Edition, 6(12): 106-130.

30. Ozturk M. (2005) A research on reliability and validity of international physical activity questionnaire and determination of physical activity level in university students. Hacettepe University Institute of Health Sciences Nutritional Sciences Program. MSc Thesis. Ankara: Hacettepe University.

31. Park N., Lee H. (2012) Social implications of smartphone use: Korean college students' smartphone use and psychological well-being. Cyberpsychol. Behav. Soc. Netw., 15(9): 491-497. DOI: 10.1089/cyber.2011.0580.

32. Park J., Kim J., Kim J., Kim K., Kim N., Choi I., Lee S., Yim J. (2015) The effects of heavy smartphone use on the cervical angle, pain threshold of neck muscles and depression. Adv. Sci. Technol. Lett., 91: 12-17.

33. Pew Research Center. (2016) Smartphone ownership and internet usage continues to climb in emerging economies. www.pewresearch.org. (accessed 25.02.2018).

34. Savcı S., Oztürk M., Arıkan H., İnal D., Tokgozoglu L. (2006) Physical activity levels of university students. Arch. Turk. Soc. Cardiol., 34(3): 166-172.

35. Shan Z., Deng G., Li J., Li Y., Zhang Y. (2013) Correlation analysis of neck/shoulder pain and low back pain with the use of digital products, physical activity and psychological status among adolescents in Shanghai. PLos One, 8(10): 78-109.

36. Silva G.R., Pitangui A.C., Xavier M.K., CorreiaJúnior M.A., De Araújo R.C. (2016) Prevalence of musculoskeletal pain in adolescents and association with computer and videogame use. J. Pediatr. (Rio J)., 92(2): 188-96. DOI: 10.1016/j.jped.2015.06.006.

37. Szerla M., Ortenburger D., Kluszczyński M., Wyszomierska J. (2017) Exercise and psychological factors in low back pain. Physical Activity Review., 5: 6-9.

38. Todd A.I., Bennett A.I., Christie C.J. (2007) Physical implications of prolonged sitting in a confined posture-a literature review. Ergonomics SA: Journal of the Ergonomics Society of South Africa, 19(2): 7-21.

39. Turkish Statistical Institute (TurkStat) (2015). TurkStat, Information and Communication Technology (ICT) Usage Survey in Households and Individuals, 2015 [Hanehalk1 Bilişim Teknolojileri Kullanım Araştırması, 2015]. http:// www.tuik.gov.tr/PreHaberBultenleri.do?id=18660 (accessed 23.8.2018).

40. Turkish Statistical Institute (TurkStat) (2016a). Turkey Health Interview Survey 2016 [Türkiye Sağlık Araştırması. 2016]. http://www.tuik.gov.tr/PreTablo. do?alt_id=1095 (accessed 25.02.2018).

41. Turkish Statistical Institute (TurkStat) (2016b). TurkStat, Survey on Information and Communication Technology (ICT) Usage Survey in Households and by Individuals, 2016 [Hanehalkı bilişim teknolojileri kullanım 
araştırması 2016]. http://www.tuik.gov.tr/PreHaberBultenleri.do?id=21779 (accessed 22.8.2018).

42. Turkish Statistical Institute (TurkStat). Individuals using the computer and Internet in the last 3 months by age groups and sex, 2004-2018. Information and Communication Technology (ICT) Usage in Households and by Individuals. http://www.turkstat.gov.tr/PreTablo.do?alt $\mathrm{id}=1028$ (accessed 10.08.2018).

43. Vassigh G. (2012) Evaluation of physical activity level sand healthy nutritional index of university students. Hacettepe University Institute of Health Sciences Nutritional Sciences Program. MSc Thesis. Ankara: Hacettepe University.

44. World Health Organization (2010). Global recommendations on physical activity for health. Geneva; Switzerland.

45. Xie Y., Szeto G.P., Dai J., Madeleine P.A. (2016) Comparison of muscle activity in using touchscreen smartphone among young people with and without chronic neck-shoulder pain. Ergonomics, 59(1): 61-72.
46. Yagcı N., Calık B.B. (2014) Investigation of effect of using desktop computers on neck pain in university students. J. Occup. Ther. Rehabil., 2(2): 65-72.

47. Y1lmazsoy B., Kahraman M. (2017) Addiction to social media and usage of the social media for educational purposes: the facebook example [Üniversite öğrencilerinin sosyal medya bağımlılı̆̆ı ile sosyal medyayı eğitsel amaçlı kullanımları arasındaki ilişkinin incelenmesi: Facebook örneği]. Journal of Instructional Technologies \& Teacher Education., 6(1): 9-20.

48. Zapata A.L., Moraes A.J., Leone C., Doria-Filho U., Silva C.A. (2006) Pain and musculoskeletal pain syndromes related to computer and video game use in adolescents. Eur, J, Pediatr., 165(6): 408-414.

Received 12.10.2018
Accepted 28.01.2019

(C) University of Physical Education, Warsaw, Poland 